(3) That the conditions are definite and easily reproducible with exactness, and that, in particular, it is impossible for the liquid, the vapor, and the thermometer to differ in temperature. The boiling points ascertained are therefore more accurate, and more exactly comparable than are those obtained by the usual method.

(4) That with impure or decomposing liquids a fractional distillation in miniature may quickly be carried out and the impureness recognized.

(5) That when the dissolved or occluded gases, or volatile substances which are always present, can be removed by boiling, the removal may be accomplished and a satisfactory boiling point secured.

(6) That by taking the boiling point of a mixture of the two, the identity or non-identity of two liquids of almost identical boiling points may often be ascertained without sacrifice of an appreciable amount of material. This method will apply, however, only when the two substances are of chemically dissimilar natures, and not usually to very similar substances. ${ }^{1}$

(7) That the method may be adapted to finding boiling points at normal pressure $(760 \mathrm{~mm}$.), and under reduced pressure (see next two papers).

[Communication from the Laboratories of General and Physical Chemistry OF THE UNIVERSITY OF ChICAgo.]

\title{
A COMMON THERMOMETRIC ERROR IN THE DETERMINATION OF BOILING POINTS UNDER REDUCED PRESSURE.
}

By Alexander Smith and alan W, C. Merzies,

Received June II, Igro.

In very accurate work, when the thermometer is immersed in a bath of liquid, a correction is introduced on account of the apparent elevation of the temperature, due to compression of the bulb. The converse effect, namely, a dilatation of the bulb, causing an apparent lowering in the temperature, when the thermometer bulb is immersed in a vapor under reduced pressure, may be equally well known. Having had occasion, however, to study a large part of the literature of boiling points and vapor pressures, we have not happened to observe any mention of this source of error, or any case in which a correction was applied on account of it. ${ }^{2}$ This source of error would appear therefore to be neglected by many chemists. Yet in the magnitude of its effects it usually far exceeds the correction for compression, since evacuation involves the removal of a pressure equivalent to a head of about 30 feet of water, while the compression involves usually the addition of only a few inches. The following observations show that, in point of fact, the effect cannot be ignored in any but the roughest work.

1 Young, Stoichiometry (London), 1908), 264.

2 Since the above was written, a single, inconspicuous instance has been noticed. 
Experiments.-Eleven thermometers (mercury in glass) of various makes were selected. Seven were graduated in tenths of a degree, and were capable of being read to hundredths. Two (Nos. 9 and ro) were graduated in fifths, and two (Nos. I and II) in hundredths of a degree. The thermometers, fitting tightly through rubber stoppers, were partially enclosed in test tubes, provided with side tubes. The tubes were supported in a thermostat, the temperature of which remained constant \pm 0.005 . After the reading of each thermometer became constant, the test tube was exhausted to $20 \mathrm{~mm}$. through the side tube, and the new reading, after constancy was reached, was taken. Air was then re-admitted, and the readings were repeated, to ascertain that no permanent change in the value at one atmosphere pressure (or more exactly $748 \mathrm{~mm}$.) had occurred.

The results are given in the table. The diameters of the bulbs are outside measurements (mm.). The thickness of the glass of the bulbs differed considerably, but could not, of course, be measured. Nos. 9 and ro were members of a set of Anschütz thermometers. No. 4 was of Jena normal glass, by Götze:

\begin{tabular}{|c|c|c|c|c|c|c|c|}
\hline \multirow[b]{2}{*}{ No. } & \multicolumn{2}{|c|}{ Bulb. } & \multirow[b]{2}{*}{ Change. } & \multirow[b]{2}{*}{ No. } & \multicolumn{2}{|c|}{ Bulb. } & \multirow[b]{2}{*}{ Change. } \\
\hline & rength. & Diam. & & & I,ength. & Diam. & \\
\hline $\mathbf{r} \ldots \ldots \ldots$ & $5^{8}$ & 5.0 & $0.144^{\circ}$ & $6 \ldots$ & 0 & $5 \cdot 5$ & $0.11^{\circ}$ \\
\hline $2 \ldots \ldots \ldots$ & 28 & 6.5 & 0.16 & $7 \ldots \ldots$ & 9 & $5 \cdot 5$ & O.II \\
\hline $3 \ldots \ldots \ldots$ & 25 & 5.0 & 0.13 & $8 \ldots \ldots$ & 10 & 5.0 & 0.10 \\
\hline $4 \ldots \ldots \ldots$ & 20 & $5 \cdot 5$ & 0.10 & $9 \ldots \ldots$ & 10 & 4.2 & 0.14 \\
\hline $5 \ldots \ldots \ldots$ & 20 & 5.0 & 0.13 & Io $\ldots \ldots$ & IO & $4 \cdot 2$ & 0.17 \\
\hline
\end{tabular}

The change in apparent temperature (dilatation) varied from o. Io to $0.17^{\circ}$. Considering the very great differences in the sizes of the bulbs, it was surprising that the changes did not cover a wider range. Evidently the amount of the effect cannot be predicted from the dimensions of the bulb.

When intermediate pressures were used, the change, as might be expected, was found to be a linear function of the pressure.

Only one of the eleven thermometers suffered a permanent distortion. In this case (No. II) the bulb measured $35 \times 9.5 \mathrm{~mm}$. The successive values of the change were $0.260^{\circ}, 0.177^{\circ}, 0.162^{\circ}, 0.162^{\circ}$ (constant).

Conclusions.-( $\mathrm{r}$ ) In vacuum distillation, if the temperatures are to be reasonably correct, special investigation of the behavior of each thermometer is required. In view of the behavior of our eleven thermometers, which showed no relation to the size of the bulb, an error much greater than $0.2^{\circ}$ might be involved in the case of an individual instrument.

(2) In measurements of vapor pressures, by methods in which the bulb of the thermometer is immersed in the vapor, an error of $0.15^{\circ}$ 
or more may exist in the temperature readings. The absence of any correction on this account vitiates many of the published data. Specific instances will be noted in later papers dealing with vapor pressures.

[Communication from the Laboratories of General and Physical Chemistry
of the University of Chicago.]

STUDIES IN VAPOR PRESSURE: II. A SIMPLE DYNAMIC METHOD, APPLICABLE TO BOTH SOLIDS AND LIQUIDS, FOR DETERMINING VAPOR PRESSURES, AND ALSO BOILING POINTS AT STANDARD PRESSURES.

By ALEXander SMith and Alan W. C MeNzies.

Received June II, Igro.

The principle of the submerged bulblet method of determining boiling points, described in the preceding paper, may be adapted to the measurement of vapor pressures. The necessary apparatus may be set up from materials found in any laboratory, and a series of measurements of considerable accuracy may be made, all with the expenditure of very little time.

The Apparatus.-The bulblet, with attached capillary tube not less than I mm. in diameter, is charged with a small amount (about o. I g.) of the solid or liquid substance, and is attached to the thermometer by means of thread or asbestos cord, just as for the boiling-point determination. Instead, however, of being then immersed directly in the open bath, it is enclosed in a test tube (see figure). The L-shaped tube leads to the manometer, connections with the atmosphere and with a pump being provided by means of T-tubes. A large bottle between the pump and manometer is useful for regulating the pressure. Stopcocks on the tube leading to the pump and on that opening to the air permit the pressure to be lowered or raised at will. For pressures below that of the atmosphere, a water-pump, and for pressures above that of the atmosphere a small

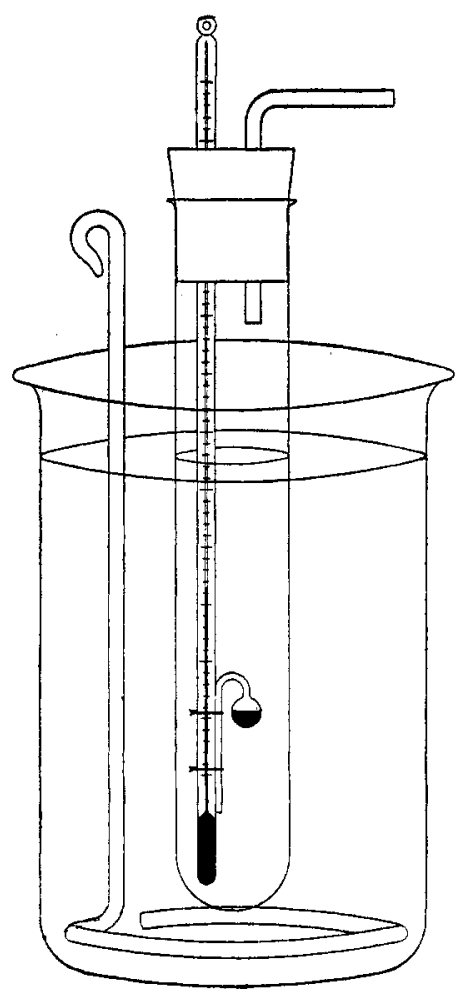
compression pump (e.g., a bicycle pump) may be used. With only a 